\title{
Joint international workshop: March 22-25 2010, Morocco
}

\author{
John Barnett
}

Published online: 18 April 2010

(C) Springer-Verlag 2010

\section{Wood and derivatives: sustainable materials and products for future needs}

This meeting was a joint initiative between the IAWS Executive Committee and 7th ESTB (School of Wood Science and Technology) with the aim of promoting wood science in Africa, a continent presently under-represented in terms of Academy Fellows. The meeting took place partly in the Faculty of Sciences, Rabat, and partly at the Al Akhawayn University, Ifrane. Position papers were presented by several fellows: Past-President Deglise on behalf of President Beall (Non-destructive evaluation methods applied to African wood and derivative industries); Antonio Pizzi (Sustainable adhesives and wood composites for developing countries), Vice President Lennart Salmen (Trends and opportunities in biorefinery) and Academy Treasurer Howard Rosen (Wood culture in the US). A further position paper was presented by Pascal Kamden of Michigan State University on challenges and opportunities in wood production. In addition to the position papers, there were 29 oral presentations and 18 posters.

A major highlight of the meeting was the presentation of the Academy Lecture by Academy executive Secretary Uwe Schmitt. His lecture was entitled "Wounding of trees, consequences and defence strategies".

The meeting was a great success with 153 delegates attending from 17 countries. In addition to a large representation from the host nation, African countries represented included Algeria, Benin, Cameroon, Nigeria, South Africa, Senegal and Togo. Delegates from nine nations outside Africa were also present. An encouraging feature was the number of young scientists who attended, promising a successful future for wood science in Africa. The meeting closed with a round table session discussing prospects for future research in Africa. In order to identify priorities it was decided to take steps towards establishing an electronic network of wood scientists and technologists throughout the continent. 
The thanks of the Executive Committee go to Professor Abdelillah Hakem and his team, who with President Beall and past-president Deglise organized this excellent meeting.

\section{Retirement announcement}

End of September 2010, Professor Dr. Gerd Wegener, editor of this journal, will retire from his position as professor of the university. He will be honoured at the 15 . Munich Wood Colloquium/“Münchener Holzkolloquium” on 6 October 2010, among others with contributions by the IAWS-Fellows Antonio Pizzi, Bjarne Holmbom and Arno Frühwald.

The final programme including registration form will be circulated in May 2010.

John Barnett

Past President of IAWS 